\title{
PSEUDOMEMBRANOUS COLITIS WITH PNEUMOPERITONEUM. SURGERY?
}

\section{Gómez Sánchez J, García-Fogeda Romero JL, Zurita Saavedra M, de Castro Monedero P, Mirón Pozo B}

Hospital Universitario San Cecilio. Granada.

\section{Resumen}

La colitis pseudomembranosa, es una patología causada por Clostridium difficile ( $C$. difficile), cuya incidencia en pacientes hospitalarios va en aumento, constituyendo hasta un $1 \%$ en los pacientes ingresados tratados con antibióticos.

El C. difficile es un bacilo Gram positivo, anaerobio con la capacidad de liberar toxinas con efecto inflamatorio y citotóxico. Casi todos los casos van precedidos de la toma de antibióticos, persistiendo el riesgo tras el cese del antibiótico, sobre todo durante el primer mes. Además, la transmisión feco-oral supone un gran riesgo de dispersión intrahospitalario y en otros ámbitos de la asistencia sanitaria.

Su gravedad, es variable, desde portador asintomático, a diarrea leve, a casos de megacolon tóxico o colitis fulminante con disfunción multiorgánica. El tratamiento en general es médico, si bien en presencia de megacolon tóxico, o refractariedad al tratamiento conservador, la cirugía presenta un papel importante en el tratamiento de la misma. En ocasiones, a pesar de pruebas de imagen indicadoras de gravedad, la decisión de cirugía puede ser precipitada, y añadir

\section{CORRESPONDENCIA}

Javier Gómez Sánchez

Hospital Clínico San Cecilio

18016 Granada

javiergomezsanchez.jg@gmail.com

Fecha de envío: 10/02/2020

Fecha de aceptación: 19/02/2020 comorbilidad al paciente, por lo que no existe un punto claro de indicación de ésta.

Se presenta el caso de un paciente colitis pseudomembranosa severa complicada que asociaba neumoperitoneo, para explicar su manejo, y cómo a pesar de presentar criterios iniciales de mal pronóstico, que abocaban por el tratamiento quirúrgico, presentó una resolución óptima con tratamiento conservador.

Palabras clave: colitis pseudomembranosa, neumoperitoneo, cirugía.

\section{Abstract}

Pseudomembranous colitis is a pathology caused by Clostridium difficile (C. difficile). Its incidence in hospitalized patients is increasing, constituting approximately $1 \%$ of hospitalized patients treated with antibiotics.

C. difficile is a Gram positive, anaerobic bacillus with the ability to release toxins with inflammatory and cytotoxic effects. Almost all cases are preceded by the consumption of antibiotics and their risk persists despite stopping the antibiotic, especially during the first month. In addition, feco-oral transmission poses a great risk of in-hospital dispersion and in other areas of health care.

Its severity is variable, from asymptomatic carrier, to mild diarrhea, to cases of toxic megacolon or fulminant colitis with 
multiorganic dysfunction. The treatment in general is medical, although in the presence of toxic megacolon, or refractory to conservative treatment, surgery has an important role in the treatment of it. Occasionally, despite imaging tests indicating severity, the decision to surgery may be precipitated, and add comorbidity to the patient, so there is no clear indication of this.

We present the case of a patient with severe complicated pseudomembranous colitis that associated pneumoperitoneum, to explain its management, and although it had initial criteria of poor prognosis, which led to surgical treatment, it presented an optimal resolution with conservative treatment.

Keywords: pseudomembranousColitis, Pneumoperitoneum, Surgery.

\section{Introducción}

C. difficile es un bacilo Gram-positivo anaerobio formador de toxinas ( $\mathrm{A}$ y $\mathrm{B}$ ) cuyo mecanismo no se conoce por completo pero están implicadas en la patogenia de la enfermedad, dada su capacidad proinflamatorias y citotóxicas, desarrollan en su forma sintomática la colitis pseudomembranosa o infección por C. difficile (ICD) ${ }^{1}$. Existen factores de riesgo como la edad avanzada, la hospitalización, y el empleo previo de antibióticos, siendo esta última el factor más frecuente, y persistiendo el riesgo de colitis tras el cese del antibiótico, sobre todo durante el primer mes$^{2}$.

La ICD tiene un alto riesgo de recurrencia e implica una morbimortalidad. Existen distintos grados de infección de acuerdo a las guías internacionales ${ }^{3,4}$ clasificándose en: leve (infección con diarrea como únicos síntomas), severa (leucocitosis $>15.000$ cels $/ \mathrm{mL}$, creatinina $>1,5 \mathrm{mg} / \mathrm{dL}$ ), severa complicada o recurrente (hipotensión o shock, íleo paralítico, necesidad de vasoactivos o megacolon tóxico,). Ante pacientes portadores pero asintomáticos no está aconsejado su tratamiento, y hasta un $25 \%$ de los pacientes puede presentar formas recurrentes en el primer mes tras la aparición de síntomas e infección ${ }^{5}$.

Se presenta el caso de una infección severa complicada por Clostridium difficile, Se presenta el caso de un paciente colitis pseudomembranosa severa complicada que asociaba neumoperitoneo, para explicar su manejo y resolución mediante tratamiento conservador.

\section{Caso Clínico}

Se presenta varón de 45 años, natural de Venezuela, residente en España de larga data, con antecedentes personales de paraparesia espástica secundaria a ependimoma intramedular resecado hace 4 años, con nivel medular aproximado desde vértebra C8 y vejiga neurógena secundaria que requiere sondaje intermitente tres veces al día, y uso de colector nocturno. Además, presentaba obesidad mórbida, SAOS sin tratamiento con CPAP y era parcialmente dependiente para las actividades diarias.
Su tratamiento habitual era de tiazinida $8 \mathrm{mg}$ (8-8-8mg), baclofeno $25 \mathrm{mg}$ (50-50-50mg), oxibutinina 3,9 mg parches (dos días por semana) y gabapentina $300-300-600 \mathrm{mg}$.

Acudió a Urgencias tras presentar episodio de dolor abdominal difuso de un día de evolución, de características opresivas asociando aumento de la espasticidad que previamente presenta. Refería que, tras una deposición de características duras, comenzó con diarrea y fiebre registrando más de 15 deposiciones. Asociaba cuadro de intensa sensación distérmica, con fiebre termometrada en domicilio de $38^{\circ} \mathrm{C}$. Interrogando al paciente, nos refiere que fue tratado hace dos semanas previas a este episodio, con Amoxicilina por posible ITU, suspendiendo el tratamiento hace tres días.

A la exploración se encontraba orientado y colaborador, aunque impresionaba de regular estado general, vigil orientado y colaborador. Tensión arterial 90/60 mm Hg, frecuencia cardiaca 85 y saturación $98 \%$.

Abdominalmente mostraba un abdomen globuloso, blando, depresible, con molestias a la palpación en fosa iliaca derecha, hipogastrio, que no empeoraba con la descompresión brusca. Ruidos hidroaéreos presentes.

Analíticamente presenta leucocitosis de 21.230 cels $/ \mathrm{mL}$ con $91 \%$ neutrófilos, una proteína $\mathrm{C}$ reactiva de $61 \mathrm{mg} / \mathrm{L}$ y procalcitonina de $23 \mathrm{ng} / \mathrm{mL}$.

Se efectuó radiología simple de abdomen con pequeña dilatación de asas de intestino delgado y colon sin signos de obstrucción. Se decidió completar el estudio mediante tomografía de abdomen con contraste destacando leve cantidad de neumoperitoneo subyacente a la pared anterior abdominal a con presencia de algunas burbujas suprahepáticas, subhepáticas y adyacente a colon ascendente (Figura 1), en probable relación con perforación de víscera hueca. Se observaba un sigma redundante con leve aumento de densidad con rarefacción de la grasa parasigmoidea además de dilatación de algunas asas de intestino delgado sin más hallazgos de interés.

En su estancia en urgencias se realizó estudio de la toxina de Clostridium difficile, siendo esta positiva para cepa A+B.

Ante estos hallazgos diagnosticándose de Colitis pseudomembranosa con criterios de gravedad (leucocitosis e hipotensión) se decidió ingreso, iniciándose tratamiento conservador con dieta absoluta y antibioterapia intravenosa con Cefepime, para la cobertura de enterobacterias por posible peritonitis secundaria, así como antibioterapia dirigida para $C$. difficile con Metronidazol y Vancomicina para cobertura de C.difficile.

Durante su ingreso, se mantiene en observación a la espera de evolución de las molestias abdominales, con pauta iniciada de Metronidazol 500 mg cada 8 horas oral, Cefepime 1 gramo cada 8 horas intravenosa y Vancomicina oral $125 \mathrm{mg}$ cada 6 horas. Presenta una evolución satisfactoria, mejorando abdominalmente, afebril, y descartándose manejo quirúrgico a pesar del neumoperitoneo inicial. Al quinto día se reinicia la ingesta oral alimentaria retirando Cefepime, y manteniendo vancomicina oral, siendo dado de alta 


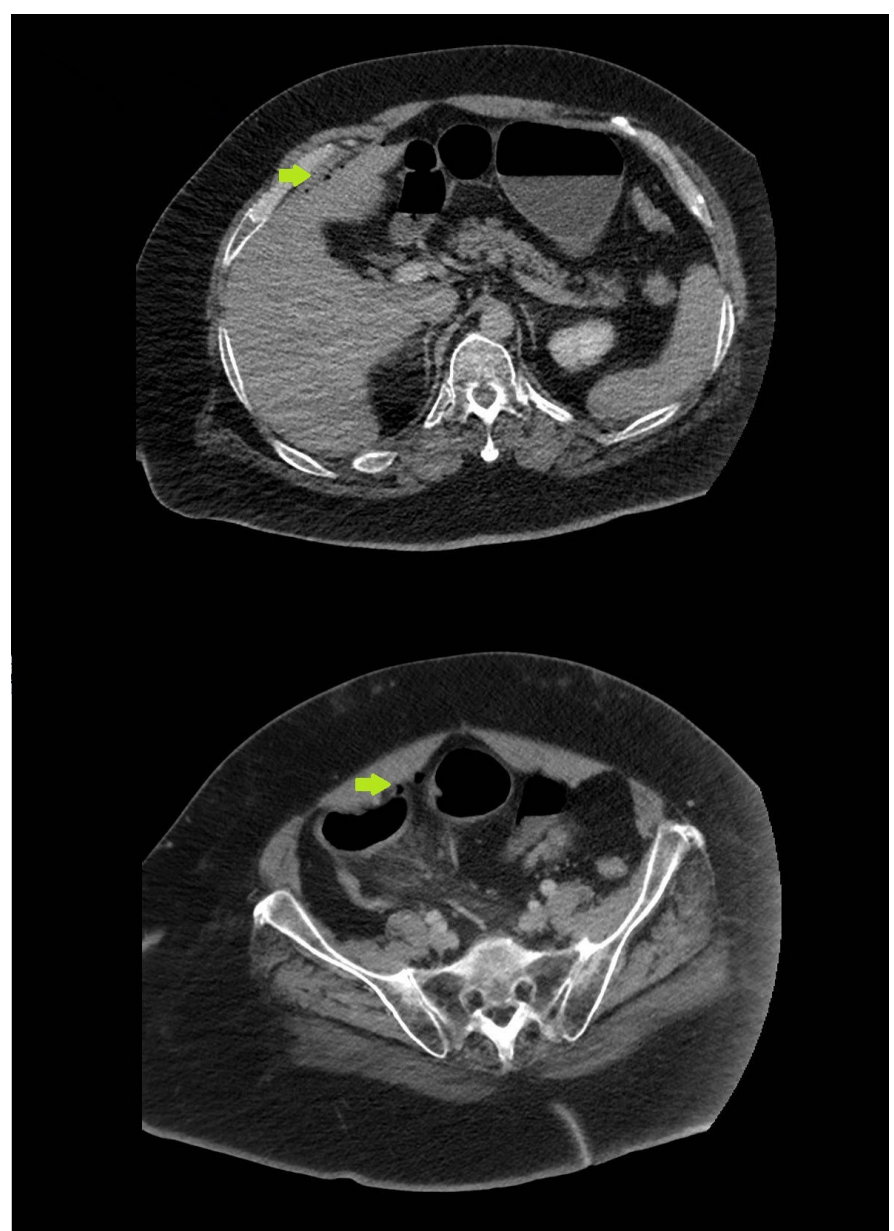

Figura 1

Tomografia abdominal donde se observan pequeñas burbujas de neumoperitoneo.

al octavo día, sin deposiciones diarreicas, completando pauta en domicilio con vancomicina hasta un total de 10 días.

Requiere reingreso posterior a los tres días del alta por episodio de disuria y fiebre, presentando sedimento urinario patológico con cultivo de $E$. Coli, con correcta resolución con Ceftazidima.

\section{Discusión}

C. difficile es un bacilo Gram positivo, formador de esporas cuyos principales factores de virulencia son la toxina $\mathrm{A}$ y la toxina B. Su mecanismo no es del todo bien conocido, pero están implicadas en la patogenia de la enfermedad su capacidad citotóxica y proinflamatoria, que aumentando la permeabilidad intestinal ${ }^{6}$. Además tiene la capacidad de formar endosporas que le permite sobrevivir durante meses en el medio hospitalario ${ }^{7}$.

Existen múltiples factores de riesgo que conducen a la aparición de esta infección, destacando la exposición previa a antibióticos, ya que se produce la alteración de la microbiota intestinal, desencadenándose una disbacteriosis intestinal que lleva a la colonización por C.difficile. En el caso de nuestro paciente, había estado expuesto a Amoxicilina/Clavulánico por la sospecha de Itu ante los sondajes vesicales reiterados. Los antibióticos más relacionado con su aparición son los de amplio espectro, sobre todo fluorquinolonas, clindamicina, cefalosporinas y penicilinas, en monoterapia o en combinación ${ }^{2}$.

La mayoría de los pacientes colonizados por Clostridium difficile se mantienen asintomáticos, siendo portadores hasta el $20 \%$ de los pacientes adultos hospitalizados La distinción entre portador asintomático e infección se realiza solo por el contexto clínico, ya que las pruebas de laboratorio no permiten su diferencia. De igual modo, pacientes colonizados pueden tener diarrea por otras causas diferentes, lo que complica aún más el correcto diagnóstico de la ICD.

Su clínica cursa con diarrea, de características acuosas, asociando en ocasiones mucosidad, y con menos frecuencia rectorragia. De forma complementaria, se acompaña de dolor abdominal, febrícula, náuseas... pudiendo derivar en cuadros graves como la colitis pseudomembranosa fulminante o el megacolon tóxico ${ }^{3}$.

Para su diagnóstico se basa principalmente en la positividad de las pruebas de laboratorio microbiológico (PCR de C. difficile y la detección de antígenos en heces) en un adecuado contexto clínico ${ }^{3,4}$. Así mismo pueden ser de ayuda otras pruebas complementarias como la tomografía abdominal, que nos permite apreciar paredes engrosadas y presencia de ascitis o líquido libre en las formas más graves. Como ocurre en nuestro caso, ante la clínica del paciente se decide complementar el estudio con un TAC, revelando un engrosamiento difuso del sigma, con alguna imagen de neumoperitoneo, sin líquido libre.

Respecto al tratamiento, es imprescindible la suspensión del antibiótico inductor, cuando sea posible ${ }^{7,8}$. El antibiótico de elección depende de la gravedad del cuadro y de si se trata de un primer episodio o una recurrencia; pero en líneas generales, el tratamiento de elección es la Vancomicina oral, tanto en casos leves como severos ${ }^{4}$, modificación respecto a anteriores guías donde se recomendaba el Metronidazol como primer escalón terapéutico. En caso de infección fulminante, se recomienda Vancomicina oral o enteral con sonda nasogástrica y/o enema (en el caso de íleo) a altas dosis (500 mg cada 6 horas) junto con Metronidazol intravenoso (500 mg cada 8 horas).

El uso de vancomicina intravenosa no está indicado al no excretarse en el colon. Existen también alternativas recientes de tratamiento como la Fidaxomicina, antibiótico con indicación tanto para primeros casos como para recidivas, y el trasplante de microbiota fecal, técnica prometedora con evidencia para el uso en casos de refractariedad a tratamiento médico así como de megacolon tóxico, si se plantease una terapia ahorradora de cirugía ${ }^{4}$. Su uso no obstante se halla sometido a estricta regulación y requiere una gran infraestructura, por lo que no se encuentra disponible en la mayoría de centros.

Una vez iniciado el tratamiento correcto, la respuesta clínica debe aparecer a las 24-48 horas, consiguiendo su resolución en más del $25 \%$ de los enfermos a los 10 días 5 .

Debemos tener en cuenta que del 3 al $8 \%$ de los infectados, pueden evolucionar a una colitis fulminante. Aunque hay situaciones claras que indican cirugía urgente, el momento exacto no está 
definido y continúa siendo en gran medida empírico. En nuestro paciente, a pesar de existir un factor de mal pronóstico como podría ser el neumoperitoneo, dada la escasa sintomatología o irritación abdominal, se decidió un manejo conservador con antibioterapia, sin plantear cirugía como primera opción terapéutica. Es decir, la presencia de neumoperitoneo, si bien es considerada un factor de mal pronóstico, no siempre se traduce en cirugía, ya que debemos contextualizar al paciente, y tener en cuenta su estado clínico.

En formas graves y refractarias, la colectomía subtotal estaría indicada si no hay mejoría clínica o existen factores de mal pronóstico, sumando una importante morbilidad al paciente, con el posible requerimiento de ostomía temporal o permanente. Aunque la colectomía es la técnica más extendida, existen otras alternativas quirúrgicas como la confección de una ileostomía con lavado anterógrado colónico intraoperatorio y postoperatorio con vancomicina ${ }^{9}$ que parece presentar resultados similares con menor morbilidad, aunque no excluya la confección de ostomía.

Si bien Neal et al. ${ }^{9}$ describieron un sistema de puntuación específico (Tabla 1) para clasificar la gravedad en función del resultado de sumar los factores del paciente, (leve 1-3, grave de 4-6 y grave complicada $>7$ ) aún no se han establecido las indicaciones concretas sobre la actuación quirúrgica, ya que no se ha establecido la puntuación necesaria para indicarla, ni qué técnica quirúrgica es la más idónea.

Tabla 1. Tabla simplificada y modificada respecto a la de Neal et $a l^{9}$, con puntuación e items para evaluar la gravedad de C. pseudomembranosa.

\begin{tabular}{|c|c|}
\hline Criterios & Puntuación \\
\hline Inmunosupresión & 1 punto \\
\hline Dolor o distensión abdominal & 1 punto \\
\hline Hipoalbuminemia<3g/dl & 1 punto \\
\hline Fiebre & 1 punto \\
\hline $\begin{array}{c}\text { Ingreso en Unidad de } \\
\text { Cuidados Intensivos }\end{array}$ & 1 punto \\
\hline $\begin{array}{c}\text { Engrosamiento mural o } \\
\text { ascitis (TAC) }\end{array}$ & 2 puntos \\
\hline $\begin{array}{c}\text { Leucocitos>15.000 o<1.500/ } \\
\text { mm3 }\end{array}$ & 2 puntos \\
\hline Creatinina>1,5 valor normal & 2 puntos \\
\hline Irritación peritoneal & 3 puntos \\
\hline Necesidad de aminas & 5 puntos \\
\hline Necesidad de ventilación & 5 puntos \\
\hline Confusión, desorientación & 5 puntos \\
\hline
\end{tabular}

Para concluir, podríamos decir que la colitis pseudomembranosa presenta un registro clínico variado, desde portador asintomático, hasta formas leves o colitis fulminantes. La evolución depende tanto de la bacteria, como de las características clínicas del paciente. Debemos considerar que existen una serie de factores de mal pronóstico, que pueden desembocar en la cirugía del paciente, pero en otras ocasiones, a pesar de existir hallazgos radiológicos desfavorables, que incitarían a la cirugía, el contexto clínico del paciente, y la mejoría evolutiva con el tratamiento conservador, puede mostrar beneficios, individualizando siempre cada caso.

\section{Bibliografía}

1. Chandrasekaran R, Lacy DB. The role of toxins in Clostridium difficile infection. FEMS Microbiol Rev. 2017 Nov 1;41(6):723-750. doi: 10.1093/ femsre/fux048.

2. Kelly C.P. Can we identify patients at high risk of recurrent Clostridium difficile infection? . Clin Microbiol Infect. 2012 Dec;18 Suppl 6:21-7. doi: 10.1111/1469-0691.12046.

3. Czepiel J, Drozdz M, Pituch H, Kuijper EJ, Perucki W, Mielimonka A, et al. Clostridium difficile infection: review. Eur J Clin Microbiol Infect Dis. 2019 Jul;38(7):1211-1221. doi: 10.1007/s10096-019-03539-6.

4. McDonald LC, Gerding DN, Johnson S, Bakken JS, Carroll KC, Coffin SE, et al. Clinical Practice Guidelines for Clostridium difficile Infection in Adults and Children: 2017 Update by the Infectious Diseases Society of America (IDSA) and Society for Healthcare Epidemiology of America (SHEA). Clin Infect Dis. 2018 Mar 19;66(7):e1-e48. doi: 10.1093/cid/cix1085.

5. Borrego García E, Martín-Lagos Maldonado A, Saucedo Villanueva MI, Narváez Ruiz AJ, Ruiz Sancho AL. Fracaso renal agudo secundario a colitis pseudomembranosa severa complicada. RAPD Online. 2018;41(3):144-146

6. Soria-Lopez E, Perez-Aisa, A. Infección por Clostridium difficile RAPD Online. 2015;38 (6):402-409.

7. Asensio A, Monge D. Epidemiología de la infección por Clostridium difficile en España. Enferm Infecc Microbiol Clin. 2012;30(6): 333-337 http://dx.doi. org/10.1016/j.eimc.2011.09.010

8. Tedesco FJ. Pseudomembranous colitis: pathogenesis and therapy. Med Clin North Am. 1982 May;66(3):655-64.

9. Neal MD, Alverdy JC, Hall DE, Simmons RL. Diverting loop ileostomy and colonic lavage. An alternative to total abdominal colectomy for the treatment of severe, complicated Clostridium difficile associated disease. AnnSurg. 2011;254:423-9. 